\title{
Difficult Biliary Cannulation in Endoscopic Retrograde Cholangiopancreatography: Definitions, Risk Factors, and Implications
}

\author{
Authors: \\ Brian M. Fung, ${ }^{1,2}$ Teodor C. Pitea, ${ }^{2}$ *James H. Tabibian ${ }^{3,4}$ \\ 1. Division of Gastroenterology and Hepatology, Department of Internal Medicine, \\ University of Arizona College of Medicine - Phoenix, Arizona, USA \\ 2. Banner - University Medical Center Phoenix, Arizona, USA \\ 3. Division of Gastroenterology, Department of Medicine, Olive View-UCLA Medical \\ Center, Sylmar, California, USA \\ 4. Vatche and Tamar Manoukian Division of Digestive Diseases, David Geffen School \\ of Medicine at UCLA, Los Angeles, California, USA \\ *Correspondence to jtabibian@dhs.lacounty.gov
}

Disclosure:

Author
contributions:

Acknowledgements:

Received:

Accepted:

Keywords:

Citation:
The authors have declared no conflicts of interest.

Fung reviewed the literature for relevant original studies and other content, designed the figures, and drafted the manuscript. Pitea and Tabibian critically reviewed the manuscript. All authors provided critical input and approved the final version of the manuscript.

This work was supported in part through the United States National Institutes of Health (NIH) grant UL1 TRO00135.

09.01.21

29.03.21

Adverse effects, endoscopic retrograde cholangiopancreatography (ERCP), guidewire-assisted cannulation, post-ERCP pancreatitis, selective biliary cannulation.

EMJ Hepatol. 2021;9[1]:64-72.

\section{Abstract}

Over the past 50 years, endoscopic retrograde cholangiopancreatography (ERCP) has become the preferred minimally invasive method of treating a vast array of pancreatobiliary diseases. An initial sine qua non for ERCP success is selective ductal cannulation. Despite significant progress in the optimisation of ERCP methods and accessories, selective biliary cannulation using conventional techniques remains unsuccessful in approximately $15 \%$ of native papilla cases. Furthermore, difficult biliary cannulation has been associated with an increased risk of post-ERCP pancreatitis, among other adverse events. Here, in the first of a two-part series, the authors provide a primer on standard biliary cannulation techniques and discuss the definition, risk factors, and implications of difficult biliary cannulation. The second part of the series will provide an overview of the existing advanced techniques used in cases of difficult biliary cannulation as well as the approach to their selection.

\section{INTRODUCTION}

In 1968, McCune et al. from George Washington University reported the first cohort of successful endoscopic biliary cannulation using an Eder

fibreoptic duodenoscope with a forward and side lens. ${ }^{1}$ Although this initial technique was only successful in $<50 \%$ of attempts, it is considered by many to be the first description of endoscopic retrograde cholangiopancreatography 
(ERCP). A year later, a side-viewing fibreoptic duodenoscope was developed in Japan by Oi et al. and was able to improve cannulation success rates to $77 \%{ }^{2}$ Over the next few years, multiple endoscopists, including Classen, Cotton, Demling, Geenen, Safrany, Siegla, Silvis, and Vennes, experimented on and improved this new technique, and by 1974, the first successful cases of endoscopic biliary sphincterotomy were reported, further paving the foundation for ERCP. ${ }^{3-5}$ These innovations, along with many other technical advances, have since transformed ERCP from a primarily diagnostic modality into an effective therapeutic technique that is now the preferred minimally invasive treatment for many pancreaticobiliary diseases. However, despite significant technological advances, ERCP is still considered a challenging procedure for many gastrointestinal endoscopists, in large part because of the failure of biliary cannulation in $5-15 \%$ of cases as well as the risk of postERCP pancreatitis (PEP) and other adverse events (AE) $)^{6,7}$

Here, in the first of a two-part series, the authors provide an overview of standard biliary cannulation techniques in patients with normal as well as altered anatomy and discuss the definition, predictors, and implications of difficult biliary cannulation. The second part of the series will provide an overview of the existing advanced techniques used in cases of difficult biliary cannulation as well as the approach to their selection.

\section{STANDARD TECHNIQUE FOR SELECTIVE BILIARY CANNULATION}

In the standard approach to selective biliary cannulation, a side-viewing endoscope (i.e., duodenoscope) is first advanced to the second part of the duodenum, wherein the major duodenal papilla is usually located in the middle third (but sometimes more proximally or distally), along the medial aspect. The duodenoscope is then positioned so that the lens and working channel are located below the major papilla. Finding the major papilla can sometimes be challenging, e.g., in the case of an intradiverticular papilla (discussed later), severe duodenal inflammation, or portal hypertensive duodenopathy, and what might initially appear to be the major papilla may not always be so (instead can be a prominent minor papilla, subepithelial lesion, or other). In general, the major papilla can be distinguished from the minor papilla based on its characteristic mucosal folds, larger size, and location approximately $2 \mathrm{~cm}$ distal to the minor papilla.

Once the major papilla is confirmed, the duodenoscope is appropriately positioned for cannulation in the vector (i.e., $x, y, z$ coordinates) of the ampulla and distal bile duct. A variety of manoeuvres are employed to align the sphincterotome for proper insertion; these can be conceptually organised into direct manipulation of the sphincterotome (e.g., bowing the tip of the sphincterotome via traction, using the elevator lever to lift the sphincterotome); manipulation of the endoscope (i.e., up/down dial, left/right dial, torquing the scope, advancing or pulling back the scope); and patient-level adjustments (e.g., changes in patient position, variable insufflation of the gastrointestinal lumen, external abdominal pressure). Once aligned, a sphincterotome or other cannulation catheter is then engaged into the orifice of the major duodenal papilla, aiming usually towards the 11 o'clock position (as compared to 2 o'clock for pancreatic duct cannulation). Historically, a cannulation catheter was the first choice for cannulation given its high flexibility and tip shape compared with the sphincterotome; however, most endoscopists now choose the sphincterotome because of its ability to bow the catheter tip by pulling or relaxing the cutting wire, facilitating alignment with the biliary duct, as well as the ability to perform sphincterotomy. Furthermore, there are data suggesting higher cannulation rates with the use of a sphincterotome over standard catheter cannulation (84-97\% versus $62-75 \%$ ). ${ }^{8-10}$

After initial engagement of (or 'seating' into) the orifice of the major papilla, the sphincterotome is subsequently advanced into the biliary duct with the assistance of either contrast or guidewire. In contrast-assisted cannulation, contrast is injected under fluoroscopy after the tip of the sphincterotome or catheter is inserted into the papillary orifice. This helps to visualise the biliary tree and provides feedback regarding catheter position. However, this technique frequently requires repetitive probing and multiple injections of contrast, factors that have been associated with higher rates of PEP." Thus, guidewire-assisted cannulation has become a 
preferred technique for most, as described in the following subsection.

\section{Guidewire-Assisted Cannulation}

Guidewire-assisted cannulation is generally the first-line method for selective biliary cannulation. ${ }^{12}$ This is largely because of several studies suggesting a lower risk of AEs, particularly PEP, with the use of a guidewire compared to contrast injection-assisted cannulation. ${ }^{13-16}$ A systematic review and metaanalysis of 12 randomised controlled trials (RCT) comprising 3,450 participants found that the risk of PEP was significantly reduced when a guidewire was used for cannulation rather than contrast injection (3.4\% versus $6.7 \%$; relative risk [RR]: 0.51; 95\% confidence interval [Cl]: 0.320.82). ${ }^{17}$ Guidewire-assisted cannulation was also associated with greater primary cannulation success rates (RR: $1.07 ; 95 \% \mathrm{Cl}: 1.00-1.15$ ) and less precut sphincterotomy (RR: 0.75; 95\% Cl: 0.600.95). ${ }^{17}$ The reduction in rate of PEP is thought to be in part because of less papillary trauma and the avoidance of contrast, which has been hypothesised to increase hydrostatic pressure within the duct, induce a chemical inflammatory response, as well as introduce bacteria into the pancreatic duct. ${ }^{18}$

In addition to the traditional technique of first inserting and 'seating' the catheter into the papillary orifice and then advancing the wire ('touch' technique), there is also the option of a 'no touch' technique, wherein the guidewire is first advanced a few millimetres out of the sphincterotome and then cannulation is attempted. However, a recent multicentre RCT found that the primary cannulation rate was higher and the mean number of cannulation attempts was lower when the touch technique was used rather than the no-touch technique (88\% versus $54 \% ; \mathrm{p}<0.001$, and 4.6 versus 5.5 attempts; $p=0.006$, respectively). ${ }^{19}$ The rate of AEs did not differ between the two techniques. Despite evidence supporting the use of the touch technique, the no-touch technique may still be useful for small or stenotic papillary orifices. ${ }^{19}$ There are also many variations of these two techniques, frequently chosen based on papillary characteristics (e.g., size, position, mobility) and physician comfort.
The most commonly used guidewire is a 0.035 inch diameter, hydrophilic-tipped guidewire. ${ }^{20}$ The use of a hydrophilic tip allows for reduced friction during advancement of the guidewire, and a 0.035 inch diameter is thought to allow for easier visualisation during fluoroscopy, among other advantages, including better tactile feel and pushability. ${ }^{21}$ However, the use of other guidewire diameters ranging from 0.018 to 0.035 inches may also be used, with two studies finding no difference in cannulation rate between the use of a 0.035 inch and 0.025 inch guidewire. ${ }^{22,23}$ Guidewires also come with various tip options, e.g., different shapes. One RCT found no difference in biliary cannulation rate between the use of a straight or angled-tip guidewire, though cannulation time appeared to be shorter with the use of an angled guidewire (20 versus $63 \mathrm{sec} ; \mathrm{p}=0.01$ ). ${ }^{24}$ More recently, a study using in vitro bile duct models suggested that an angled-tip guidewire had a higher cannulation success rate compared to other types of guidewires. ${ }^{25} \mathrm{~J}$-tip and loop-tip guidewires have also been evaluated and do not appear to have significantly different biliary cannulation rates than more conventional guidewires. ${ }^{26,27}$ Overall, differences in cannulation outcomes attributable to tip shape alone are likely minimal among experienced endoscopists but may be important in early endoscopists and in select scenarios (e.g., variant anatomy).

Despite the widespread use of guidewireassisted cannulation, it is important to note that not all studies have found a decrease in incidence of PEP with this technique. ${ }^{28-30}$ The use of an assistant to manipulate the guidewire may also be associated with a higher rate of complications. ${ }^{3}$ Furthermore, the use of a guidewire has its own risks, including the risk of the creation of a false tract, pancreatic duct injury, and perforation. ${ }^{32}$ Thus, the potential drawbacks of this technique should be appreciated in order to reduce AE and increase success rates.

\section{DIFFICULT BILIARY CANNULATION: MYRIAD CONSIDERATIONS}

Selective biliary cannulation fails in 5-15\% of cases, even in the hands of experienced endoscopists. ${ }^{33}$ In such scenarios, collectively referred to as 'difficult biliary cannulation', the endoscopist must decide whether to continue with standard 
cannulation techniques, switch to more advanced techniques, consult a more senior colleague (if available), or abort the procedure and consider re-attempting at a later time. The urgency of the procedure, duration of the procedure, availability of requisite accessories, logistical and cost factors, and likelihood of increased AE risk are all important considerations in this decision. ${ }^{11,34,35}$

\section{DEFINITION OF DIFFICULT BILIARY CANNULATION}

How difficult biliary cannulation is defined varies considerably in the published literature. ${ }^{36}$ Most studies define difficult cannulation based on the number of cannulation attempts (typically between five and 15) and/or the time spent on cannulation (typically greater than 5-30 min). 13,29,35 The number of unintentional passages or contrast injections into the pancreatic duct should also be considered, as these correlate with cannulation difficulty and increase the risk of PEP. ${ }^{37,38}$ A prospective study found that after five attempts, the risk of PEP increased from $6.1 \%$ to $11.9 \%{ }^{39}$ The European Society of Gastrointestinal Endoscopy (ESGE) has defined difficult biliary cannulation as the presence of more than five contacts with the papilla while attempting to cannulate, more than 5 min spent attempting to cannulate, or more than one unintended passage or contrast injection into the pancreatic duct. $^{20,39}$ This definition was validated in a recent study by Ismail et al. ${ }^{40} \mathrm{~A}$ recent international consensus guideline has suggested a slightly different definition, defining difficult biliary access as the inability to achieve selective biliary cannulation by standard ERCP techniques within 10 min or after up to five cannulation attempts, or the inability to access the major papilla (e.g., because of gastric outlet obstruction or Roux-en-Y anatomy). ${ }^{41}$

In addition to variations in the definition of difficult biliary cannulation, there is also no standardised definition for a cannulation attempt. In a study by Friedland et al., a cannulation attempt was described to be any repositioning or wedging of the cannulation device while attempting biliary cannulation. ${ }^{42}$ However, others have defined cannulation attempt as an intentional continuous contact with the papilla; Bailey et al. defined an attempt as sustained contact for at least 5 sec. ${ }^{11,39}$ Similarly, and perhaps for this reason, quantification of the number of cannulation attempts may be subjective. A prospective study by Tian et al. found that inter-observer variability in the assessment of cannulation attempts was high, and that cannulation time appeared to be a more objective and accurate tool for assessing cannulation difficulty. ${ }^{43}$

\section{RISK FACTORS FOR DIFFICULT BILIARY CANNULATION}

The likelihood of difficult biliary cannulation is based on both operator and patient factors. In the following subsections, the authors describe some of the factors which may impact the risk of difficult biliary cannulation.

\section{Endoscopist Factors}

As one may expect, increased experience with ERCP is associated with higher cannulation success rates. ${ }^{44} \mathrm{~A}$ success rate of $80 \%$ has been suggested as the goal during ERCP training. ${ }^{45}$ This success rate appears to require a minimum of 200 ERCP examinations. ${ }^{46}$ One study found that cannulation rate increased from $43 \%$ to $280 \%$ after $350-400$ supervised procedures, with success rate continuing to improve to $>96 \%$ post-training. ${ }^{47}$ Routine performance of ERCP also appears to be required to maintain ERCP proficiency, as lower provider volume has been associated with a higher failure rate and a greater need for post-procedure hospitalisation. ${ }^{48-50}$ One study showed that a second-attempt ERCP at an ERCP referral centre had a success rate of $>95 \%$ after having an initial failed attempt at a lower volume hospital. ${ }^{51}$

\section{Patient Factors}

The success of selective biliary cannulation fundamentally depends on careful alignment of the sphincterotome (or other cannulating catheter) with the vector of the papillary orifice, hepatopancreatic ampulla, and distal common bile duct (CBD). Thus, variations in these structures or factors that affect visualisation, positioning, and manoeuvrability in this regard can increase cannulation difficulty. A normal papilla has four main anatomical parts: orifice, frenulum, hood, and infundibulum (Figure 1), each of which can vary significantly (Figure 2). ${ }^{52}$ 


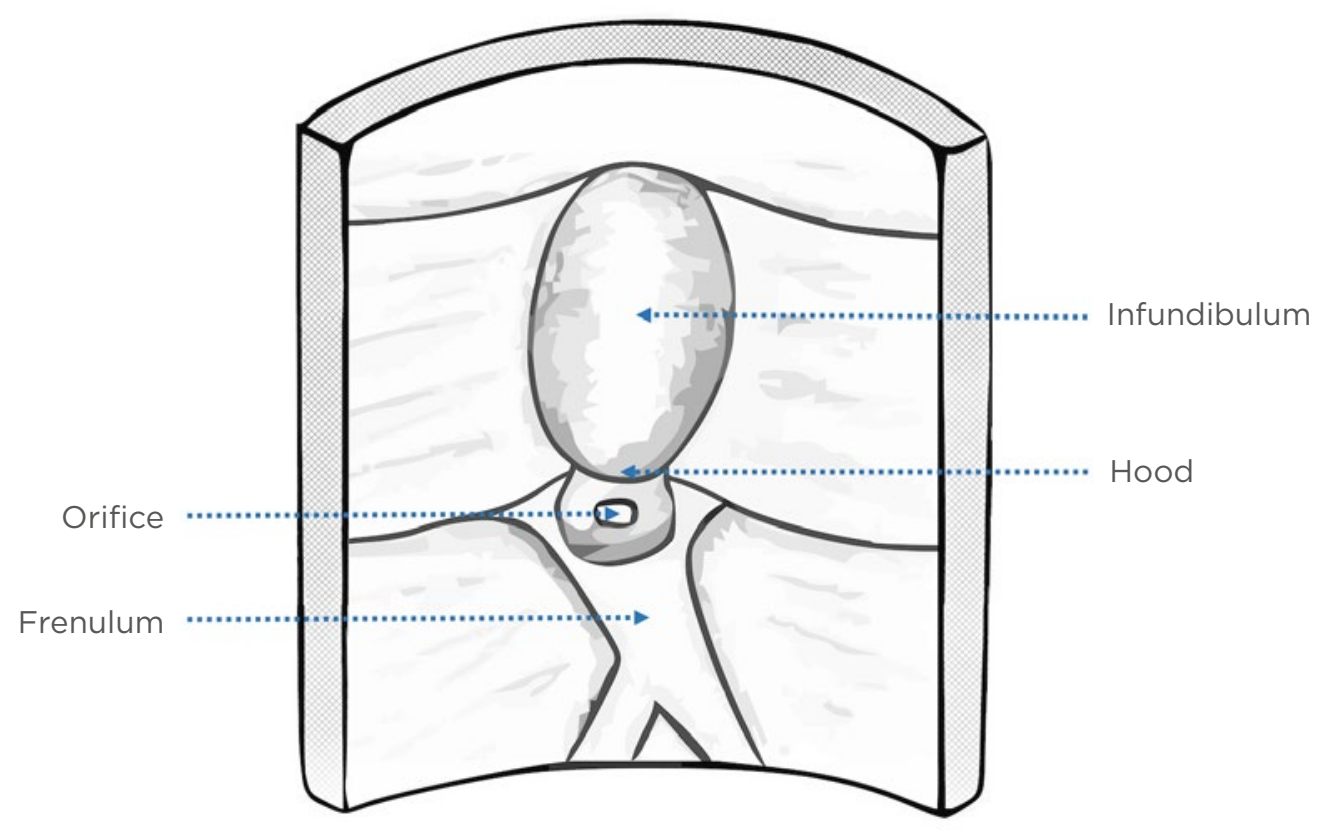

Figure 1: Diagram of normal papillary anatomy showing the four main anatomical features.
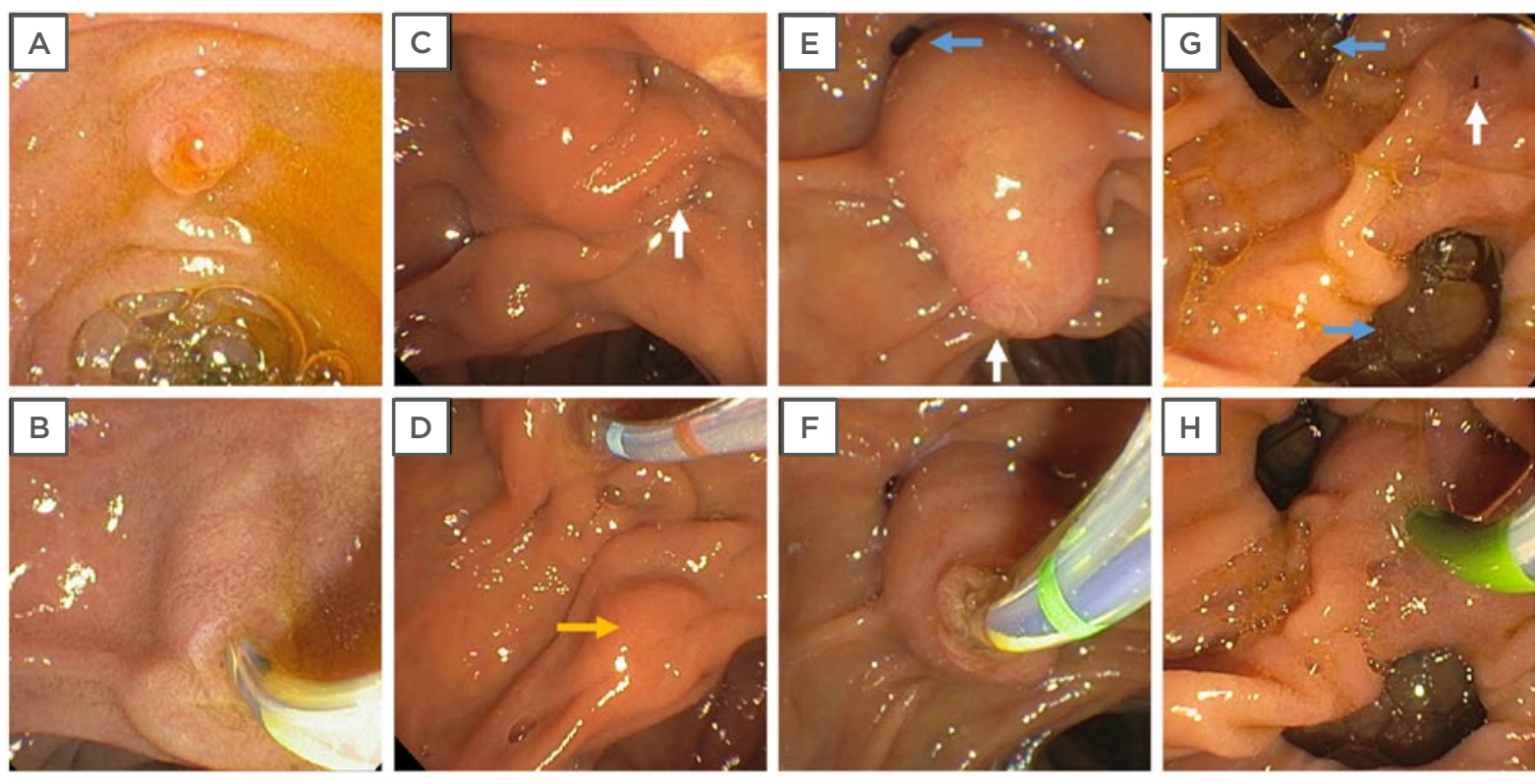

Figure 2: Examples of anatomical variations in the major duodenal papilla.

A) Normal native papilla. B) Biliary cannulation is achieved with conventional techniques using a tapered-tip (3.9 Fr outer diameter) sphincterotome. C) Papilla with tortuous distal portion of the infundibulum and drooping hood, the latter limiting visualisation of the papillary orifice (white arrow), which is oriented to the right. D) Cannulation is achieved using a sphincterotome (4.4 Fr distal tip outer diameter). A submucosal lesion (yellow arrow) is incidentally seen just distal to the papilla and was initially mistaken for the papilla. E) Large, protuberant papilla with its orifice oriented downwards and to the left. The papillary appearance is suggestive of an impacted ampullary stone, and a juxtapapillary diverticulum (blue arrow) is also incidentally noted just proximal to the papilla. F) Cannulation is readily achieved using a sphincterotome; had this not been successful, a precut suprapapillary fistulotomy could have been performed to release the suspected stone. G) A diminutive, flat, interdiverticular papilla, with duodenal diverticula (blue arrows) immediately proximal and distal to it. H) Cannulation is achieved using a tapered-tip sphincterotome. 
In the following sub-section, the authors describe the papillary characteristics, as well as location, peripapillary findings (e.g., diverticulum, lipoma, duplication cyst), and surgically altered anatomies that can make selective biliary cannulation difficult.

Papillae come in many sizes and morphologies, and a classification system has been previously developed to describe these characteristics and their implications on biliary cannulation. ${ }^{53}$ Small papillae are often more difficult to identify (discussed further below), especially when there is significant duodenal oedema, inflammation, or redundant mucosal folds, and thereafter cannulate. ${ }^{54} \mathrm{~A}$ small papilla increases the odds of the sphincterotome coming in contact with the septum instead of insertion into the bile duct, especially if highly compressible, and may make it more difficult to make adjustments to the position of the sphincterotome without losing contact with the papilla. On the other hand, a large papilla may be more relaxed and floppy, providing less stability during cannulation. ${ }^{55}$ Protuberant papillae also appear to have higher rates of difficult cannulation, be this because of an impacted stone or otherwise. ${ }^{55}$ Advanced age and sex have not been found to be associated with increased rates of difficult biliary cannulation. ${ }^{56,57}$

Although the hepatopancreatic ampulla (and hence the major papilla) usually enters the duodenum in the second portion, it is occasionally located at the superior duodenal angle or in the third portion of the duodenum, making the papilla more difficult to identify and/ or reach. ${ }^{58}$ The papilla can also be hidden behind overlying folds; lifting the folds gently with the tip of a catheter can sometimes reveal the papilla. In some cases, the papilla can be difficult to locate because of tumour infiltration into the papilla/ duodenum or pancreatitis causing oedema of the duodenum. ${ }^{59}$ Increased tissue friability and bleeding in cases of malignancy can decrease visibility of the ampulla. Extra-papillary pathology can also decrease access to the papilla. Benign or malignant narrowing of the gastric outlet, duodenal bulb, or second part of the duodenum proximal to the papilla can prevent adequate access and positioning for biliary cannulation. ${ }^{60}$ In some cases, endoscopic dilation with or without the placement of a self-expanding metallic stent is first required. ${ }^{61}$
It is known that intradiverticular and peridiverticular papillae can increase cannulation difficulty. ${ }^{62}$ One report found the success rate for cannulation of peridiverticular papillae to be $62.4 \%$ versus $92.7 \%$ when there is no diverticulum. ${ }^{63}$ These herniations of the mucosa or submucosa are found in up to $15 \%$ of patients undergoing ERCP. ${ }^{64}$ When the papilla is found on the edge of or within a diverticulum, it can obscure the papilla or distort its orientation, to the extent where the pancreatic and biliary orifice locations can be reversed. A variety of approaches, including the 'no-touch' technique, ${ }^{65}$ have been reported to facilitate cannulation in such cases, depending on the specific nature of the diverticula and the anatomic relation of the major papilla to them.

The level of sedation may also impact cannulation success rate. A case-control study of 31,001 ERCP procedures found that the use of propofol was associated with higher cannulation success rate (89\% versus $86.7 \% ; \mathrm{p}<0.0001$ ) and fewer intra-procedural complications $(2.9 \%$ versus $3.7 \%$; $p<0.0001$ ) compared with the use of moderate sedation (midazolam in combination with opioids) ${ }^{66}$

\section{Surgically Altered Anatomy}

Patients with surgically altered anatomy such as post Billroth II gastrectomy or post-Rouxen- $Y$ gastric bypass present with a unique set of challenges, ${ }^{67,68}$ and ERCP in these patients is generally performed at referral centres by endoscopists who have experience with these types of anatomical alterations..$^{51,69}$ In patients who are post Billroth II, a standard duodenoscope can be used because of the short distance to the papilla through the afferent loop. However, determining the afferent from the efferent limb can be challenging, and approaching the papilla from the opposite direction can be disorienting. On the other hand, ERCP in patients who have had a Roux-en-Y requires the use of a longer length endoscope (or a direct transgastric approach) because of the need to transverse a large length of small bowel prior to reaching the descending duodenum. This requires the use of a colonoscope or enteroscope, both of which are forward-viewing instruments that are not designed for ERCP. Similar to Billroth II cases, recognising the proper intestinal lumen and selective cannulation from the opposite direction can be challenging. 


\section{IMPLICATIONS OF DIFFICULT BILIARY CANNULATION}

PEP is the most common complication of ERCP, resulting in significant cost and morbidity. ${ }^{6,70}$ Although minor variations are found in the literature, the ESGE currently defines PEP as new or worsened abdominal pain combined with $>3$ times the normal value of amylase or lipase at more than 24 hours after ERCP and admission or prolongation of a planned admission. ${ }^{12}$ It is thought to occur because of a number of contributing factors, including increased hydrostatic pressure within the duct with contrast, mechanical trauma, thermal injury from electrosurgical current during sphincterotomy, and chemical inflammation from contrast-injection. ${ }^{18}$ In meta-analyses, the incidence of PEP varies from 3.5-9.7\%, with the majority of cases being mild and a mortality rate of only $0.1-0.7 \% .6,70$ However, in cases of difficult biliary cannulation, the incidence of PEP is higher (odds ratio: 1.76-14.9), ${ }^{12}$ likely because of increased manipulation of the papilla leading to tissue oedema and higher frequency of inadvertent cannulation of the pancreatic duct.

Various measures have been found to help reduce the risk of PEP aside from cannulation technique, such as rectal indomethacin, aggressive intravenous fluid hydration (preferably with lactated Ringer's solution), and pancreatic duct stenting; an overview of these methods can be found in the American Society for Gastrointestinal Endoscopy (ASGE) and ESGE guidelines. ${ }^{12,71}$ Of note, pancreatic duct stent placement can also help facilitate bile duct access in cases of difficult biliary cannulation, in addition to reducing the risk of PEP.
Difficult biliary cannulation is also associated with increased risk of bleeding and perforation. 12,72 A case-control study examining ERCP-related perforations found that difficult biliary cannulation was an independent risk factor for perforation. ${ }^{72}$ Specifically, periampullary perforation resulting from biliary or pancreatic sphincterotomy or precut techniques (Stapfer Type II perforations) and perforations of the bile duct or pancreatic duct caused by instrumentation or stenting (Stapfer Type III perforations) can occur. ${ }^{71,73}$ Thus, difficult biliary cannulation is negatively impactful on a variety of clinical levels.

\section{CONCLUSION}

Over the past several decades, ERCP has become an indispensable tool in the diagnosis and treatment of many pancreaticobiliary diseases. However, despite technological advances, it remains a challenging procedure, with selective biliary cannulation being one of the key ratelimiting steps during ERCP. Difficult biliary cannulation, generally defined by the number of cannulation attempts and/or the time spent on cannulation, is more likely to occur in cases where variations in native anatomical structures or surgically altered anatomy affect visualisation, positioning, and manoeuvrability during ERCP. Endoscopist-dependent factors may also affect the risk of difficult biliary cannulation. Despite advances in cannulation techniques, difficult biliary cannulation is often associated with an increased rate of complications, particularly PEP, because of increased manipulation of the papilla and pancreatic duct. The second part of this series will provide an update and overview of the existing advanced techniques used in cases of difficult biliary cannulation as well as the approach to their selection.

\section{References}

1. McCune WS et al. Endoscopic cannulation of the ampulla of vater: a preliminary report. Ann Surg. 1968;167(5):752-6.

2. Oi I. Fiberduodenoscopy and endoscopic pancreatocholangiography. Gastrointest Endosc. 1970;17(2):59-62.

3. Classen M, Demling L. Endoskopische sphinkterotomie der papilla Vateri und steinextraktion aus dem ductus choledochus. Dtsch Med Wochenschr. 1974;99(11):496-7. (In German).

4. Kawai $\mathrm{K}$ et al. Endoscopic sphincterotomy of the ampulla of Vater. Gastrointest Endosc. 1974;20(4):148-51.

5. McHenry L, Lehman G, "Approaching
50 Years," Kozarek RA, Baron TH (eds.), The Future of ERCP (2017) 3rd edition, Philadelphia, PA: SaundersElsevier, pp.1-6.e1.

6. Andriulli $A$ et al. Incidence rates of post-ERCP complications: a systematic survey of prospective studies. Am J Gastroenterol. 2007;102(8):1781-8. 
7. Harewood GC, Baron TH. An assessment of the learning curve for precut biliary sphincterotomy. Am J Gastroenterol. 2002;97(7):1708-12.

8. Schwacha $\mathrm{H}$ et al. A sphincterotomebased technique for selective transpapillary common bile duct cannulation. Gastrointest Endosc. 2000;52(3):387-91.

9. Cortas GA et al. Selective cannulation of the common bile duct: a prospective randomized trial comparing standard catheters with sphincterotomes. Gastrointest Endosc. 1999;50(6):775-9.

10. Laasch $\mathrm{HU}$ et al. Comparison of standard and steerable catheters for bile duct cannulation in ERCP. Endoscopy. 2003;35(8):669-74.

11. Bailey AA et al. Needle-knife sphincterotomy: factors predicting its use and the relationship with post-ERCP pancreatitis (with video). Gastrointest Endosc. 2010;71(2):26671.

12. Dumonceau JM et al. ERCP-related adverse events: European Society of Gastrointestinal Endoscopy (ESGE) Guideline. Endoscopy. 2020;52(2):12749.

13. Artifon ELA et al. Guidewire cannulation reduces risk of postERCP pancreatitis and facilitates bile duct cannulation. Am J Gastroenterol. 2007;102(10):2147-53.

14. Bailey AA et al. A prospective randomized trial of cannulation technique in ERCP: effects on technical success and postERCP pancreatitis. Endoscopy. 2008;40(4):296-301.

15. Lee TH et al. Can wire-guided cannulation prevent post-ERCP pancreatitis? A prospective randomized trial. Gastrointest Endosc. 2009;69(3 Pt 1):444-9.

16. Cheung $\mathrm{J}$ et al. Guidewire versus conventional contrast cannulation of the common bile duct for the prevention of post-ERCP pancreatitis: a systematic review and metaanalysis. Gastrointest Endosc. 2009;70(6):1211-9.

17. Tse F et al. Guidewire-assisted cannulation of the common bile duct for the prevention of post-endoscopic retrograde cholangiopancreatography (ERCP) pancreatitis. Cochrane Database Syst Rev. 2012;12:CD009662.

18. Tryliskyy Y, Bryce G. Post-ERCP pancreatitis: pathophysiology, early identification and risk stratification. Adv Clin Exp Med. 2018;27(1):149-54.

19. Bassi $\mathrm{M}$ et al. A multicenter randomized trial comparing the use of touch versus no-touch guidewire technique for deep biliary cannulation: the TNT study. Gastrointest Endosc. 2018;87(1):196201.
20. Testoni PA et al. Papillary cannulation and sphincterotomy techniques at ERCP: European Society of Gastrointestinal Endoscopy (ESGE) Clinical Guideline. Endoscopy. 2016;48(7):657-83.

21. McCarthy $\mathrm{JH}$ et al. Cannulation of the biliary tree, cystic duct and gallbladder using a hydrophilic polymer-coated steerable guide wire. Gastrointest Endosc. 1990;36(4):3869.

22. Kitamura $\mathrm{K}$ et al. 0.025 -inch vs 0.035 -inch guide wires for wire-guided cannulation during endoscopic retrograde cholangiopancreatography: A randomized study. World J Gastroenterol. 2015;21(30):9182-8.

23. Bassan MS et al. The impact of wire caliber on ERCP outcomes: a multicenter randomized controlled trial of 0.025-inch and 0.035-inch guidewires. Gastrointest Endosc. 2018;87(6):1454-60.

24. Vihervaara $\mathrm{H}$ et al. Angled- or straight-tipped hydrophilic guidewire in biliary cannulation: a prospective, randomized, controlled trial. Surg Endosc. 2013;27(4):1281-6.

25. Kwon $\mathrm{Cl}$ et al. Technical reports of endoscopic retrograde cholangiopancreatography guidewires on the basis of physical properties. Clin Endosc. 2020;53(1):65-72.

26. Tsuchiya T et al. Effectiveness of the J-tip guidewire for selective biliary cannulation compared to conventional guidewires (The JANGLE Study). Dig Dis Sci. 2015;60(8):2502-8.

27. Hwang JC et al. A prospective randomized study of loop-tip versus straight-tip guidewire in wire-guided biliary cannulation. Surg Endosc. 2018;32(4):1708-13.

28. Kawakami $\mathrm{H}$ et al. A multicenter, prospective, randomized study of selective bile duct cannulation performed by multiple endoscopists: the BIDMEN study. Gastrointest Endosc. 2012;75(2):362-72, 372.e1.

29. Mariani A et al. Guidewire biliary cannulation does not reduce postERCP pancreatitis compared with the contrast injection technique in low-risk and high-risk patients. Gastrointest Endosc. 2012;75(2):33946.

30. Kobayashi G et al. Wire-guided biliary cannulation technique does not reduce the risk of post-ERCP pancreatitis: Multicenter randomized controlled trial. Dig Endosc. 2013;25(3):295-302

31. Buxbaum $\mathrm{J}$ et al. Randomized trial of endoscopist-controlled vs. assistantcontrolled wire-guided cannulation of the bile duct. Am J Gastroenterol. 2016:111(12):1841-7.

32. Takano $\mathrm{Y}$ et al. Perforation of the papilla of vater in wireguided cannulation. Can Gastroenterol Hepatol. 2016; DOI: $10.1155 / 2016 / 5825230$

33. Cennamo $\mathrm{V}$ et al. Can early precut implementation reduce endoscopic retrograde cholangiopancreatography-related complication risk? Meta-analysis of randomized controlled trials. Endoscopy. 2010;42(5):381-8

34. Katsinelos $P$ et al. Risk factors for therapeutic ERCP-related complications: an analysis of 2,715 cases performed by a single endoscopist. Ann Gastroenterol. 2014;27(1):65-72

35. Testoni PA et al. Risk factors for post-ERCP pancreatitis in high- and low-volume centers and among expert and non-expert operators: a prospective multicenter study. Am J Gastroenterol. 2010;105(8):1753-61.

36. Tabibian JH, Leung JW. Training in ERCP: a multifaceted enterprise now more than ever. Endosc Int Open. 2018:6(1):E90.

37. Lee YS et al. Difficult biliary cannulation from the perspective of post-endoscopic retrograde cholangiopancreatography pancreatitis: identifying the optimal timing for the rescue cannulation technique. Gut Liver. 201;15(3):45965.

38. Dumonceau J-M et al. Prophylaxis of post-ERCP pancreatitis: European Society of Gastrointestinal Endoscopy (ESGE) Guideline Updated June 2014. Endoscopy. 2014:46(9):799-815.

39. Halttunen $\mathrm{J}$ et al. Difficult cannulation as defined by a prospective study of the Scandinavian Association for Digestive Endoscopy (SADE) in 907 ERCPs. Scand J Gastroenterol. 2014;49(6):752-8.

40. Ismail $\mathrm{S}$ et al. Criteria for difficult biliary cannulation: start to count. Eur J Gastroenterol Hepatol. 2019;31(10):1200-5

41. Liao WC et al. International consensus recommendations for difficult biliary access. Gastrointest Endosc. 2017;85(2):295-304.

42. Friedland $\mathrm{S}$ et al. Bedside scoring system to predict the risk of developing pancreatitis following ERCP. Endoscopy. 2002;34(6):483-8.

43. Tian $\mathrm{C}$ et al. Cannulation time is a more accurate measure of cannulation difficulty in endoscopic retrograde cholangiopancreatography than the number of attempts. Gastroenterol Rep. 2013;1(3):193-7.

44. Guda N, Freeman M. Are you safe for your patients - how many ERCPs should you be doing? Endoscopy. 2008:40(8):675-6.

45. Wicks $A C B$ et al. Structured training 
and assessment in ERCP has become essential for the Calman era. Gut. 1999;45(1):154-6.

46. Wani $S$ et al. Setting minimum standards for training in EUS and ERCP: results from a prospective multicenter study evaluating learning curves and competence among advanced endoscopy trainees. Gastrointest Endosc. 2019;89(6):11608.e9.

47. Verma D et al. Establishing a true assessment of endoscopic competence in ERCP during training and beyond: a single-operator learning curve for deep biliary cannulation in patients with native papillary anatomy. Gastrointest Endosc. 2007;65(3):394-400.

48. Coté GA et al. Lower provider volume is associated with higher failure rates for endoscopic retrograde cholangiopancreatography. Med Care. 2013;51(12):1040-7.

49. Freeman ML et al. Complications of endoscopic biliary sphincterotomy. N Engl J Med. 1996;335(13):909-18.

50. Loperfido S et al. Major early complications from diagnostic and therapeutic ERCP: a prospective multicenter study. Gastrointest Endosc. 1998;48(1):1-10.

51. Choudari CP et al. Success of ERCP at a referral center after a previously unsuccessful attempt. Gastrointest Endosc. 2000;52(4):478-83.

52. Balan GG et al. Anatomy of major duodenal papilla influences ERCP outcomes and complication rates: a single center prospective study. J Clin Med. 2020;9(6):1637.

53. Haraldsson E et al. Macroscopic appearance of the major duodenal papilla influences bile duct cannulation: a prospective multicenter study by the Scandinavian Association for Digestive Endoscopy Study Group for ERCP. Gastrointest Endosc. 2019;90(6):957-63.

54. Chen PH et al. Duodenal major papilla morphology can affect biliary cannulation and complications during ERCP, an observational study. BMC Gastroenterol. 2020;20(1):310.

55. Watanabe $M$ et al. Transpapillary biliary cannulation is difficult in cases with large oral protrusion of the duodenal papilla. Dig Dis Sci. 2019;64(8):2291-99.

56. Tabak F et al. Endoscopic retrograde cholangiopancreatography in elderly patients: Difficult cannulation and adverse events. World J Clin Cases. 2020;8(14):2988-99.

57. Vihervaara $\mathrm{H}$ et al. Female gender and post-ERCP pancreatitis: is the association caused by difficult cannulation? Scand J Gastroenterol. 2011:46(12):1498-502

58. Baillie J. Difficult biliary access for ERCP. Curr Gastroenterol Rep. 2012;14(6):542-7.

59. Anderloni AA et al. Tu1437 difficult biliary cannulation in patients with distal malignant biliary obstruction: a restrospective analysis of a single center experience. Gastrointest Endosc. 2018;87(6):AB598.

60. Nabi Z, Reddy DN. Endoscopic management of combined biliary and duodenal obstruction. Clin Endosc. 2019:52(1):40-6

61. Wang GC et al. Combined intestina and biliary stenting in gastric outlet and biliary obstruction. Gastroenterol Res. 2009;2(1):29-34.

62. Altonbary AY, Bahgat $\mathrm{MH}$. Endoscopic retrograde cholangiopancreatography in periampullary diverticulum: the challenge of cannulation. World J Gastrointest Endosc. 2016;8(6):282-7.

63. Lobo DN et al. Periampullary diverticula: consequences of failed ERCP. Ann R Coll Surg Engl. $1998 ; 80(5): 326-31$

64. Hochberger J et al, "Difficult cannulation and sphincterotomy," Chandrasekhara $\mathrm{V}$ et al (eds.), Clinical Gastrointestinal Endoscopy (2019) 3rd edition, Elsevier, pp.563-570.e2.

65. Zimmer V. Gastrointestinal: no touch-guidewire cannulation in periampullary diverticulum. J Gastroenterol Hepatol. 2020;35(8):1261.

66. Hallerbäck B, Enochsson L. A prospective nationwide study on the impact of the level of sedation on cannulation success and complications of endoscopic retrograde cholangiopancreatography. Ann Gastroenterol. 2020;33(3):299-304.

67. Krutsri $\mathrm{C}$ et al. Current status of endoscopic retrograde cholangiopancreatography in patients with surgically altered anatomy. World J Gastroenterol. 2019:25(26):3313.

68. Enestvedt BK et al. Devices and techniques for ERCP in the surgically altered GI tract. Gastrointest Endosc. 2016;83(6):1061-75.

69. Moreels TG. Endoscopic retrograde cholangiopancreatography in patients with altered anatomy: How to deal with the challenges? World J Gastrointest Endosc. 2014;6(8):34551.

70. Kochar B et al. Incidence, severity, and mortality of post-ERCP pancreatitis: a systematic review by using randomized, controlled trials. Gastrointest Endosc. 2015;81(1):143-9. e9.

71. Chandrasekhara $\vee$ et al. Adverse events associated with ERCP Gastrointest Endosc. 2017;85(1):32-47.

72. Weiser $\mathrm{R}$ et al. Management of endoscopic retrograde cholangiopancreatography-related perforations: experience of a tertiary center. Surgery. 2017;161(4):920-9.

73. Stapfer M et al. Management of duodenal perforation after endoscopic retrograde cholangiopancreatography and sphincterotomy. Ann Surg. 2000;232(2):191-8. 